OBINGER, Herbert; LEIBFRIED, Stephan \& CASTLES, Francis (eds.). 2005. Federalism and the Welfare Sta$t e$ : New World and European Experiences. New York : Cambridge University.

\title{
INTERAÇÕES ENTRE FEDERALISMO E POLÍTICAS SOCIAIS
}

\author{
Vanessa Elias de Oliveira
}

Quais as relações entre federalismo e políticas sociais e de que forma estas últimas são atingidas pelo desenho institucional federativo são as questões centrais da coletânea de artigos/estudos de caso apresentados por Herbert Obinger, Stephan Leibfried e Francis Castles em Federalism and the Welfare State: New World and European Experiences. Centrando atenção nos países desenvolvidos, sejam do Velho (Áustria, Alemanha e Suíça) ou do Novo Mundo (Austrália, Canadá e Estados Unidos), os trabalhos enfocam os efeitos recíprocos decorrentes da interação entre essas duas "macrovariáveis", demonstrando que embora tenha um peso significativo, "federalismo" não é a única variável explicativa para os baixos níveis de gastos sociais nas federações, quando comparadas a países com o mesmo grau de desenvolvimento. Com isso, o trabalho relativiza a força das análises - tão disseminadas na Ciência Política contemporânea - que asseveram que países federativos gastam menos em políticas sociais do que países unitários, além de gerarem maiores desigualdades regionais (PETERSON, 1995; LINZ \& STEPAN, 2000; TREISMAN, 2002).

O livro, em contraposição, demonstra que mais do que uma relação de causalidade, o que se verifica nas federações é uma relação de reciprocidade, em que não apenas o federalismo influencia as políticas sociais, mas estas também têm um impacto sobre o desenvolvimento futuro dos sistemas federativos, principalmente no que diz respeito ao tipo de relacionamento intergovernamental resultante: se mais ou menos centralizado, com maior ou menor poder dos diferentes níveis de governo. Além disso, minora o peso da variável dummy "federalismo", afirmando que esta não é, necessariamente, a melhor variável explicativa para os níveis de gastos sociais dos países: "uma vez que o federalismo não representa um conjunto uniforme de arranjos institucionais no tempo e no espaço, seria uma assunção heróica afirmar que o seu impacto no desenvolvimento dos sistemas de proteção social dá-se de maneira similar nos diferentes países. As diversidades entre países quanto às instituições federativas, as diferentes interfaces entre instituições governamentais, diferentes sistemas partidários e sistemas de intermediação de interesses, assim como as diferentes constelações de atores com preferências heterogêneas, estratégias e interesses, constituem uma ampla gama de configurações institucionais, tornando extremamente improvável que o federalismo esteja associado com padrões uniformes de políticas sociais e trajetórias de desenvolvimento similares em todos os países" (p. 29, tradução da autora).

Trabalhando dentro do campo do neo-institucionalismo e ancoradas na perspectiva da "dependência de trajetória" (path dependence), ou seja, na idéia de que fatos históricos e escolhas passadas influenciam e delimitam o campo de ação dos atores com relação ao rol de caminhos a serem seguidos no futuro (PIERSON, 2000; 2004), as análises apresentadas partem de uma distinção entre as eras de ouro e de austeridade das políticas sociais, demonstrando como muitas das escolhas feitas pelos atores políticos no presente são reflexos de decisões tomadas no período de surgimento das políticas sociais em cada um dos países.

A hipótese central defendida pelos autores, derivada das análises de ambos os períodos, é que o federalismo exerce um "efeito catraca" institucional (institutional "ratchet effect"), obstruindo tanto o desenvolvimento de novos sistemas de proteção social quanto as iniciativas de contração daqueles já maduros. Dessa maneira, corroboram o diagnóstico feito por Pierson (1994), há mais de uma década, sobre a era da austeridade nos Estados Unidos e na Inglaterra. Paul Pierson à época demonstrou que, em primeiro lugar, o sucesso das medidas de retração das políticas sociais fora menor do que o esperado em ambos os países, remanescendo intactos os principais componentes dessas políticas; em segundo lugar, que o grau de retração das políticas variou não apenas de um país para o outro, mas também de política para política dentro de cada país, dependendo do grau de consolidação (burocrática e perante a opinião pública) das instituições e do poder de barganha dos atores políticos que as defendiam; e, por fim, que embora o sucesso das reformas tenha sido limitado, as medidas adotadas podem abrir um flanco para futuros cortes. 
O caso do Canadá, apresentado por Keith Banting, ilustra bem esse ponto. Em um primeiro momento do Welfare State canadense verificou-se um lento desenvolvimento das políticas sociais, marcado por uma forte descentralização. Dos anos 1940 a meados dos anos 1970 houve um aumento da presença do governo federal, gerando uma gradual expansão das políticas de proteção social, que serviram não apenas como políticas de diminuição das desigualdades sociais, mas também - ou principalmente, como sugere o autor - como mecanismo de integração nacional, num país marcado pelo movimento separatista dos quebequenses. Todavia, ainda que a expansão das políticas sociais tenha sido lenta e diminuta, quando comparada àquela realizada em outros países desenvolvidos, ela deu-se em um ambiente repleto de atores com poder de veto (veto players), como os eleitores, os partidos oposicionistas e as próprias províncias, que serviram de barreira, no momento seguinte, às medidas de retração das políticas sociais. A estrutura federativa descentralizada serviu, ela mesma, para a manutenção de programas e serviços sociais já em vigor, uma vez que os governos provinciais perceberam que seriam eleitoralmente prejudicados por medidas tomadas pelo governo central e, por isso, pressionaram-no e barraram as tentativas de cortes nos gastos sociais.

Da mesma forma, o trabalho sobre a Austrália, apresentado por Francis Castles e John Uhr, demonstra que ainda que "a era de ouro" do Welfare State australiano tenha sido tímida em termos de gastos per capita, se comparados aos de outros países da Organização para a Cooperação e o Desenvolvimento Econômico (OCDE) à época, a expansão dos gastos públicos voltados para as políticas sociais realizada pelo Partido Trabalhista nos anos 1970 gerou, no momento seguinte, o efeito catraca apontado, impedindo a diminuição drástica dos gastos e das estruturas centrais das políticas sociais em vigor. Assim, embora o recurso per capita despendido na Austrália com tais políticas seja inferior ao gasto em outros países desenvolvidos, mas unitários, tal montante não pode ser explicado apenas pelo fato de ser a Austrália uma federação; a ascensão do Partido Trabalhista ao poder contribuiu imensamente para a expansão das políticas sociais e, ademais, a consolidação da política criou uma dificuldade de ordem eleitoral que impediu cortes maiores nos gastos a elas destinados.

O caso norte-americano, emblemático nos estudos acerca dos baixos níveis de gastos sociais nas federações, também reforça a tese defendida no livro, de que o federalismo não inibe, a priori, tais gastos. Partindo de uma revisão do desenvolvimento das políticas sociais norte-americanas, Kenneth Finegold demonstra que o federalismo teve uma dupla atuação, em diferentes momentos históricos: ora aumentou, ora restringiu os gastos públicos. Cinco pontos principais explicam como o federalismo interage e influencia o desenvolvimento das políticas sociais: a) o federalismo pressupõe diferenças regionais, verificadas no nível de desenvolvimento das políticas sociais, com grande variação de estado para estado; b) a competição entre os estados para atrair investimentos gera o que Peterson (1995) chamou de race to the bottom - a diminuição do investimento público em serviços sociais pelos estados norte-americanos com o objetivo de desestimular a imigração de cidadãos menos abastados, que são aqueles que mais se utilizam desses serviços e, com isso, gerar recursos extras voltados para a diminuição de impostos e atração de investimentos privados; c) a atuação do governo federal muitas vezes é contida em função da necessidade de emendamento constitucional, o que é extremamente difícil, dado as árduas regras institucionais do sistema político norte-americano; d) os estados servem de "laboratórios" para as inovações em políticas sociais, que podem ser nacionalmente ampliadas quando bemsucedidas regionalmente, facilitando a atuação federal a posteriori e e) o sistema federativo pode ampliar a gama de resultados possíveis em políticas sociais não consensuais, por estar aberto a negociações com os estados.

A Alemanha, por sua vez, justamente por não contar com tantos pontos de veto e possuir um caráter mais centralizador, preserva um dos mais altos dispêndios nessa área como porcentagem do produto interno bruto (PIB) na Europa, trazendo assim mais uma evidência - ainda que baseada em um argumento diverso - de que a relação entre federalismo e gasto social nem sempre é direta e, menos ainda, inequívoca. Assim, Philip Manow assevera que não basta saber se dado país é ou não uma federação para se fazer inferências sobre o volume de recursos despendidos com políticas sociais; é preciso levar em consideração o tipo de relacionamento entre estados e governo federal, ou seja, se o federalismo é cooperativo ou competitivo e - acrescento - se é mais ou menos centralizado. De acordo com ele, "onde as instituições federativas criam uma jurisdição conjunta sobre as políticas sociais, 'federalismo' não apresenta, necessariamente, um efeito de constrangimento ao crescimento do gasto social” (p. 224). Somado ao caráter cooperativo do federalismo, evidenciado pela existência de uma política de redistribuição dos recursos fiscais capaz de minorar as desigualdades regionais, Manow demonstra que grande parte do sucesso das políticas sociais alemãs encontra-se no fato de que há uma forte centralização das decisões nas mãos do governo federal, desde as primeiras legislações sociais, com Bismarck. As características centralizadora e equalizadora do federalismo alemão contribuíram para o desenvolvimento do Estado 
de Bem-estar Social, tanto na "era de ouro", quanto na "era da austeridade", quando houve a diminuição da participação dos recursos federais e aumento do financiamento via fundos de seguridade social, mas que, ainda assim, não retirou o país do posto de um dos maiores "investidores" em políticas sociais do mundo.

$\mathrm{Na}$ Áustria, a expansão das políticas sociais deu-se em um ambiente conservador e não democrático, e a interação entre políticas sociais e federalismo não foi uma via de mão dupla, já que grande parte da política social fora implementada em ambiente não federativo. Por essa razão é que Herbert Obinger afirma que há poucas evidências, para o caso austríaco, de que o federalismo tenha influenciado o desenvolvimento das políticas sociais, tanto na sua fase de crescimento quanto na de "austeridade". Durante a monarquia foram introduzidos alguns seguros sociais, mas que eram financiados pelas contribuições de patrões e empregados, sem o subsídio do Estado. Em 1920 a Áustria tornou-se um Estado federativo, com forte assimetria de poderes em favor do governo central e pouca alteração tanto no que tange às responsabilidades dos níveis de governo, quanto em termos de políticas sociais. Após novo interregno, fascista, a Áustria inicia a "era de ouro" das políticas sociais como um dos maiores investidores em proteção social do mundo como porcentagem do PIB padrão que foi pouco alterado nos anos 1990, pois, conforme apontou o autor: "desde 1986 todo governo tem conseguido maioria no Conselho Federal [...], não [tendo sido feito] uso do veto na legislação sobre política social” (p. 215-216). Assim, a política social austríaca tanto corrobora a hipótese central do livro, de que não há uma correlação necessária entre federalismo e gasto social, quanto põe em xeque a literatura que afirma ser o Welfare State um "subproduto" das democracias.

Por fim, a Suíça é vista pelos autores (Obinger, Armingeon, Bonoli e Bertozzi) como um sistema federativo que agrega características tanto do federalismo alemão quanto do norte-americano. Como nos Estados Unidos, a federação visa permitir a manutenção das diferenças entre os territórios constituintes da federação (os cantões). Por outro lado, tal como no federalismo alemão, os cantões têm uma relação cooperativa entre si e com o governo federal, dado que são eles que administram e implementam a maior parte das políticas federais. No entanto, uma característica fundamental do federalismo suíço o distingue dos demais: o mecanismo de democracia direta. Sempre que solicitada por 50 mil assinaturas de eleitores, toda tentativa de emendamento constitucional e de aprovação de leis deve ser submetida a referendo, dificultando as mudanças no sentido de transferir poder dos estados para a União e, portanto, retardando ou impedindo a introdução dos programas sociais federais. Somadas a isso, quatro características fortemente institucionalizadas do federalismo suíço têm conseqüências para o desenvolvimento das políticas sociais: primeira, o governo federal não pode legislar sobre uma política pública se não estiver constitucionalmente autorizado - caso contrário, é preciso haver um emendamento constitucional, via referendo; segunda, a Constituição permite diferenciações regionais significativas, tanto de taxação quanto de provisão de serviços públicos, promovendo grandes desigualdades regionais; terceira, não existem contribuições federais diretas e permanentes - apenas temporárias, dependendo da aprovação periódica do parlamento e dos eleitores; quarta, o governo central é fortemente dependente do aparato administrativo dos 26 cantões e três mil municípios, sendo eles que implementam grande parte dos programas federais. O grande número de veto players obstaculizou o desenvolvimento das políticas sociais nas duas "eras" do Welfare State, mas, por outro lado, também serviu de barreira contra cortes nos gastos públicos na era de "austeridade": os referendos, que anteriormente haviam bloqueado uma maior interferência do governo federal nas políticas sociais, foram instrumentos importantes, no momento seguinte, à manutenção dos níveis de gastos até então realizados.

Enfim, a tese de Obinger, Castles e Leibfried parece confirmar-se, ao menos nas seis federações analisadas, onde a estrutura federativa exerceu influência sobre o rumo das políticas sociais, ora servindo como barreira ao seu desenvolvimento, ora como veto às medidas de diminuição do Estado de Bem-Estar Social em vigor. Ademais, os casos apresentados no livro robustecem o argumento de que o federalismo não afeta as políticas sociais de maneira uniforme e que, por outro lado, as políticas sociais influenciam o rumo dos sistemas federativos, alterando-os ao longo do tempo, ainda que com variações de federação para federação. Noutras palavras, as interações entre federalismo e políticas sociais são recíprocas, influenciadas pelo tempo e pelo espaço.

Ao mesmo tempo, a existência ou não de federalismo não é a única variável explicativa, conforme salientam. Outras, como o partido no governo, o grau de dificuldade de emendamento constitucional, o número de pontos de veto do sistema, o papel da Suprema Corte, a participação popular via referendos, a assimetria de poderes etc., compõem o puzzle decorrente das interações entre federalismo e políticas sociais. Ao apresentar estudos de caso, Federalism and the Welfare State explicita os detalhes históricos dessas interações, demonstrando como cada variável tem pesos diferenciados em contextos históricos distintos. Conseqüentemente, "[...] a 
aparente correspondência entre federalismo e tipo de Estado de Bem-Estar Social desaparece, com um alto grau de variação tanto institucional quanto estrutural dos sistemas de proteção social, nos federalismos do Velho e do Novo Mundo" (p. 318).

Nesse sentido, o trabalho comparado apresentado pelos autores segue a linha de pesquisa iniciada por Pierson (1995), que procurou demonstrar que outras variáveis políticas, além do federalismo, interferem nos resultados alcançados pelas políticas sociais. De acordo com o autor, grandes análises quantitativas comparadas, comuns nesse campo de pesquisa, deixam de lado características institucionais peculiares de cada país, encobrindo o poder explicativo dessas variáveis. Em resumo, o "federalismo tem uma grande relevância para o desenvolvimento da política social, mas como ele importa depende dos tipos específicos de federalismo e como as instituições federativas estão envolvidas em contextos políticos particulares" (PIERSON, 1995, p. 451; grifo no original).

É fato que o livro trabalha dentro de um campo de pesquisa já consolidado - e, nesse sentido, pouco inovador: a influência dos atores com poder de veto sobre o resultado das políticas públicas, demonstrando que quanto maior o número de pontos de veto, maiores as dificuldades de mudança da política, seja para ampliá-la ou para diminuí-la. Todavia, o livro explora um "subcampo" específico e ainda pouco cultivado, que trata da atuação desses atores em contextos federativos e de sua interação com as políticas sociais. Este e outros trabalhos têm procurando captar tal interação não apenas nos países em desenvolvimento (CASTLES, 1999; RODDEN, 2005), como também no Brasil e na América Latina (ARRETCHE, 2006) e a sua contribuição para os estudos sobre políticas sociais parece ser incontestável, principalmente em função da desmistificação do peso da variável "federalismo".

Vanessa Elias de Oliveira (van.elias@uol.com.br) é Mestre em Ciência Política pela Universidade de São Paulo (USP) e doutoranda em Ciência Política pela mesma instituição, tendo realizado doutorado-sanduíche na Universidade de Colúmbia (Estados Unidos) como bolsista da Coordenação de Aperfeiçoamento do Pessoal de Nível Superior (Capes).

\section{REFERÊNCIASBIBLIOGRÁFICAS}

ARRETCHE, M. 2006. Coordinating Policies in a Fragmented Federal State : the Brazilian Case. Artigo apresentado no XX Congresso da Associação Internacional de Ciência Política, realizado em Fukuoka (Japão), de 9 a 13 de julho. Digit.

CASTLES, F. 1999. Comparative Public Policy: Patterns of Post-War Transformation. Chelenham : E. Elgar.

LINZ, J. \& STEPAN, A. 2000. Inequality Inducing and Inequality Reducing Federalism : with A Special Reference to the Classic Outlier - the USA. Artigo apresentado no XVIII Congresso da Associação Internacional de Ciência Política, realizado na cidade de Quebeque (Canadá). Digit.

PETERSON, P. 1995. The Price of Federalism. New York : Twentieth Century Fund.

PIERSON, P. 1994. Dismantling the Welfare State? Reagan, Thatcher, and the Politics of Retrenchment. Cambridge : Cambridge University.

1995. Fragmented Welfare States : Federal Institutions and the Development of Social Policy. Governance : International Journal of Policy and Administration, London, v. 8, n. 4, p. 449-478, Oct.

. 2000. Increasing Returns, Path Dependence, and the Study of Politics. American Political Science Review, Washington, D. C., v. 94, n. 2, p. 251-267, June.

. 2004. Politics in Time. History, Institutions, and Social Analysis. Princeton : Princeton University.

RODDEN, J. 2005. Federalismo e descentralização em perspectiva comparada : sobre significados e medidas. Revista de Sociologia e Política, Curitiba, v. 24, p. 9-27, jun.

TREISMAN, D. 2002. Defining and Measuring Decentralization : A Global Perspective. Disponível em : http:/ /www.polisci.ucla.edu/faculty/treisman/defin.pdf. Acesso em : 15.dez.2006. 